\title{
Investigation and optimization of an untypical vertical axis rotor of a small wind turbine
}

\author{
Frank KORTENSTEDDE, Jan Mathias STIEF
}

DOI: 10.30464/jmee.2019.3.3.245

Cite this article as:

Kortenstedde F., Stief J. M. Investigation and optimization of an untypical vertical axis rotor of a small wind turbine. Journal of Mechanical and Energy Engineering, Vol. 3(43), No. 3, 2019, pp. 245-258.

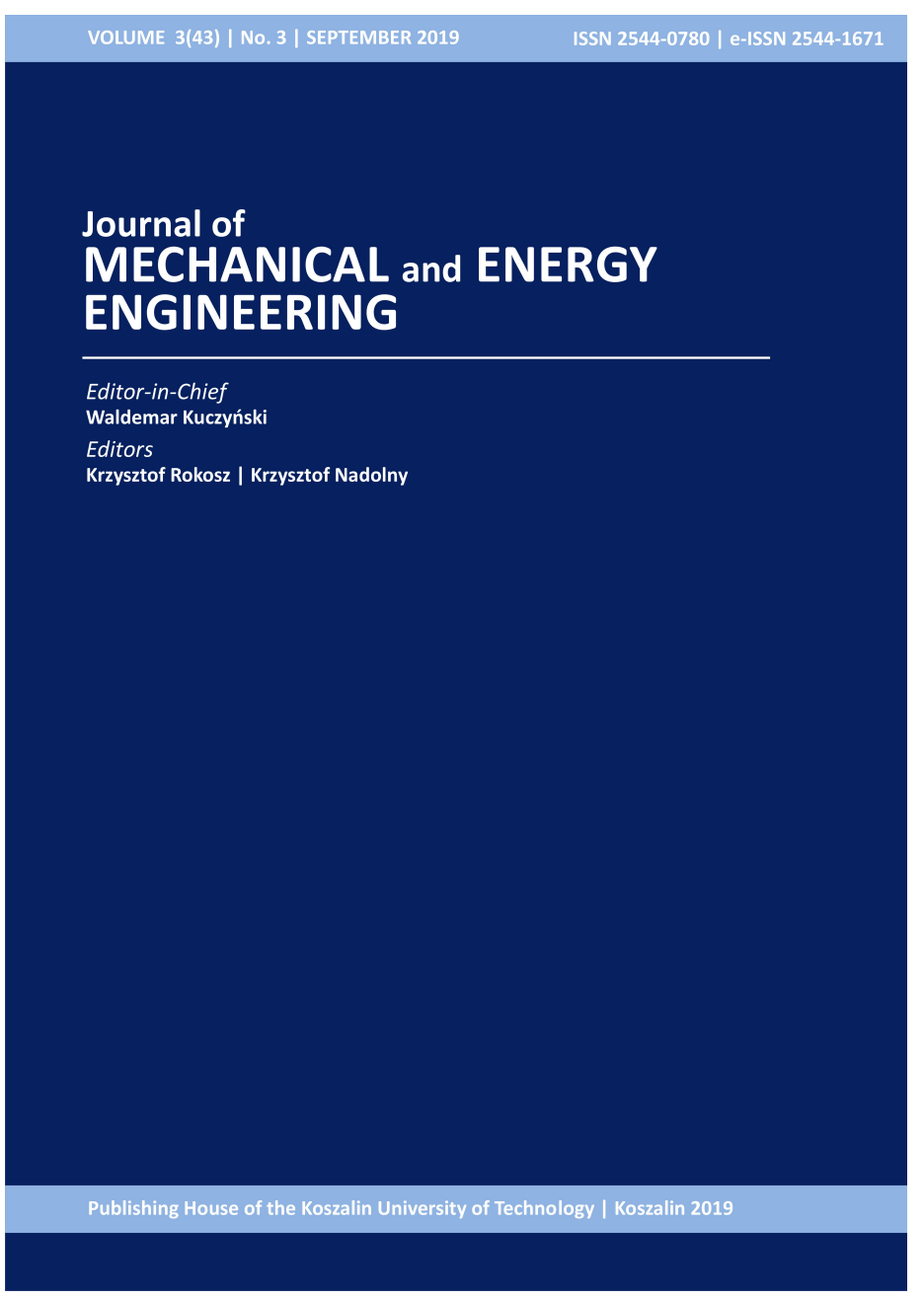

Journal of Mechanical and Energy

Engineering

Website: jmee.tu.koszalin.pl

ISSN (Print): $2544-0780$

ISSN (Online): 2544-1671

Volume: 3(43)

Number: 3

Year: 2019

Pages: 245-258

Article Info:

Received 13 November 2019

Accepted 27 November 2019

\section{Open Access}

This article is distributed under the terms of the Creative Commons Attribution 4.0 (CC BY 4.0) International License (http://creativecommons.org/licenses/by/4.0/), which permits unrestricted use, distribution, and reproduction in any medium, provided you give appropriate credit to the original author(s) and the source, provide a link to the Creative Commons license, and indicate if changes were made. 


\title{
INVESTIGATION AND OPTIMIZATION OF AN UNTYPICAL VERTICAL AXIS ROTOR OF A SMALL WIND TURBINE
}

\author{
Frank KORTENSTEDDE ${ }^{1 *}$, Jan Mathias STIEF $^{2}$ \\ ${ }^{1 *}$ City University of Applied Sciences, Faculty of Nature and Engineering, Institute of Aerospace \\ Technology, Flughafenallee 10, 28199 Bremen, Germany, e-mail: Frank.Kortenstedde@hs-bremen.de \\ ${ }^{2}$ City University of Applied Sciences, Faculty of Nature and Engineering, Institute of Aerospace Technology
}

(Received 13 November 2019, Accepted 27 November 2019)

\begin{abstract}
In this paper, an atypical resistance rotor of a vertical axis small wind energy turbine is to be aerodynamically investigated and later on optimized in a flow simulation. In this report the results obtained from the flow simulations of the single and two rotor setup, as well as the results from the flow simulations of a single blade, are presented. The geometry of the rotor and blades is the base geometry for further optimization. All simulations are performed with one specific tip speed ratio. The base geometry for slat and baffle can be calculated based on experience gained in previous studies. It was found in previous experiments that a rotor with $42 \%$ coverage (area that occupies the wings of the total circumference) is always started. Those experiments have also shown that a rotor with $36.5 \%$ coverage has a higher power coefficient at low wind speeds, at higher wind speeds, the rotor with $42 \%$ coverage has a better power coefficient. Based on those first investigations the optimization of the blade and rotor geometry will be carried out later in this project. Another focal point will be the investigation of the "stacking" of two wind turbines on top of each other in order to obtain a stable torque over the entire circulation and the determination of the optimal distance between two rotors.
\end{abstract}

Keywords: wind energy, vertical axis wind turbine

\section{INTRODUCTION}

The use of wind as a renewable source of energy is very common nowadays. Most of the energy produced by wind comes from wind farms, in which large horizontal axis wind turbines are used [1,2]. However, the energy of the wind flowing over higher buildings in cities or detached houses is mostly unused. A possible way of making this energy usable is the installation of arrays of small wind turbines. Such wind turbines need to be simple, long-lasting and of low-maintenance and should amortize themselves in a reasonable time frame. Horizontal axis wind turbines have the disadvantage that they need to be turned depending on the wind direction, leading to a mechanically more complex system and the need of control mechanisms. Vertical axis wind turbines are independent from the wind direction, as long as the array of turbines is positioned perpendicular to the main wind direction. Therefore, less mechanical complex and cheaper systems can be realized [3 , 4]. Most of the vertical axis wind turbines are drag driven turbines, which limits the reachable power coefficient [2]. In this project a small vertical axis wind turbine, based on the c-rotor design [5], is first aerodynamically investigated and later optimized. The goal of the aerodynamic investigations is to identify potential for optimization. This optimization can include the optimization of the blade profiles [3], to make more use of the generated lift and shift the turbine more to a lift driven then a drag driven turbine, the stacking of turbines [6] to obtain a more stable torque and the varying of the distance between the turbines [7]. Especially with a lift driven turbine higher power coefficient are reachable [8]. In this paper the aerodynamic investigations conducted so far are described and the results are presented and discussed. The optimization of the vertical axis rotor will be the next step of this project. 


\section{METHODOLOGY}

As a starting point for this project, the energy generated by rotors of different diameter and height is estimated with the help of preliminary calculations [9]. Based on those calculations two rotor sizes are chosen for the CFD analysis, performed with Ansys Fluent (Ansys Version 17.2), one rotor with a height and diameter of one meter and a rotor with a height and diameter of $0.8 \mathrm{~m}$. The geometry of the c-rotor-blades is calculated based on the equations presented in [9] and is dependent on the chosen diameter and coverage. The equations themselves are based on previous studies and experiments. For the coverage a value of $42 \%$ is chosen, since rotors with this value seem to be the most versatile referring to [9]. However different coverage values will be investigated later in this project. Based on the chosen blade-geometry a simple scalable 3DCAD-model of the rotor is created, seen in figure 1 . The top and bottom covers are included since it is expected that they have an influence on the overall performance of the rotor (avoiding pressure equalization [4]).

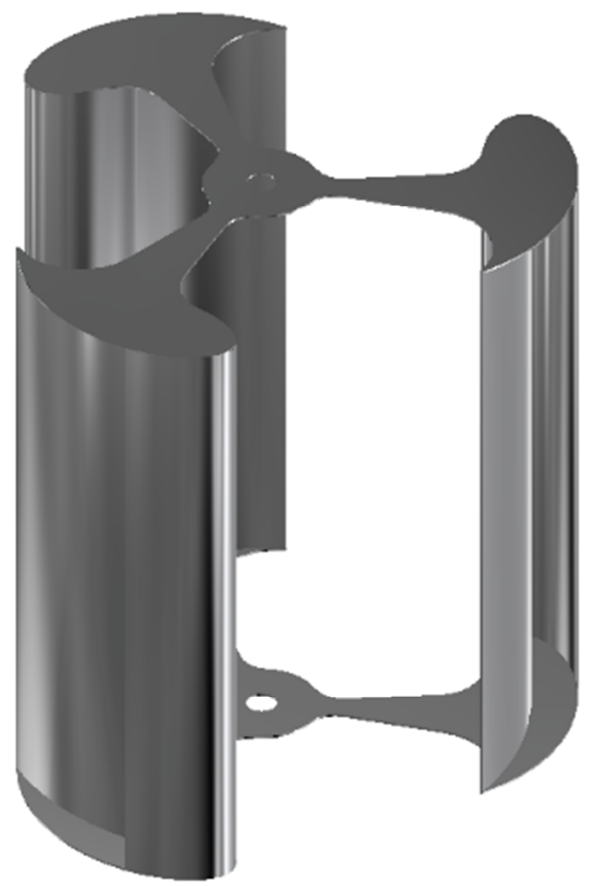

Fig. 1. CAD-Model of the C-Rotor
Three different transient CFD-analysis are performed:

- $\quad$ single rotor with a diameter and height of $0.8 \mathrm{~m}$,

- two rotors with a diameter and height of $1 \mathrm{~m}$,

- two rotor-setup with reversed direction of rotation.

Since it is planned that one system consists of multiple rotors, the two simulations of two rotors are performed in order to examine the effects the rotors have on each other and the effect different directions of rotation may have on the power coefficient (cp) [7].

The rotors are rotated with the calculated RPM (Revolutions per Minute) based on the expected tipspeed-ratio of 0.65 , which again is based on [9] and [10] and the expected average wind speed of $5 \mathrm{~ms}-1$, which is based on [11] and [12]. This leads to a RPM of $77.59 \mathrm{~min}-1$ for the rotor with a diameter $0.8 \mathrm{~m}$ and $62 \mathrm{~min}-1$ for the rotor with a diameter of $1 \mathrm{~m}$. In a later stage of the project a simulation of the fluid and rigid body interaction is planned [13]. Using such a simulation, the rotation of the rotors is based on the flow instead of being artificial, however such an analysis is much more time consuming. Each analysis runs over two full rotations of the rotors, leading to a simulation time of $1.6 \mathrm{~s}$ for the rotor with a diameter of $0.8 \mathrm{~m}$ and $2 \mathrm{~s}$ for the rotor with a diameter of $1 \mathrm{~m}$. For the rotor with a diameter of $0.8 \mathrm{~m}$ a farfield with a width of $30 \mathrm{~m}$ and a total height of $42.5 \mathrm{~m}$, a distance of $15 \mathrm{~m}$ in front of the rotor and $30 \mathrm{~m}$ behind the rotor, is created, seen in figure 2 . The rotor is placed 0.5 mabove the ground. For the two rotor setup, a farfield with a width of $30 \mathrm{~m}$ and a total height of $25 \mathrm{~m}$, a distance of $15 \mathrm{~m}$ in front of the rotors and $30 \mathrm{~m}$ behind the rotors, is created, seen in figure 3 . Again, the rotors are placed $0.5 \mathrm{~m}$ above the ground. Figures 4 and 5 show the two different two rotor setups with different directions of rotation. The air is flowing in negative $\mathrm{z}$-direction. The two rotors are placed $0.7 \mathrm{~m}$ away from each other for the first iteration, measured from outer diameter to outer diameter, based on [7]. For the simulations, the pressure-based solver and the coupled scheme are chosen in addition with the shear stress transport k- $\omega$ model. For the spatial discretization first order upwind schemes are chosen for momentum, turbulent kinetic energy $(k)$ and the specific dissipation rate $(\omega)$. For the gradient the least squares cell-based method is chosen and for pressure the second order scheme [13]. For the temporal discretization the first order implicit scheme is chosen. 


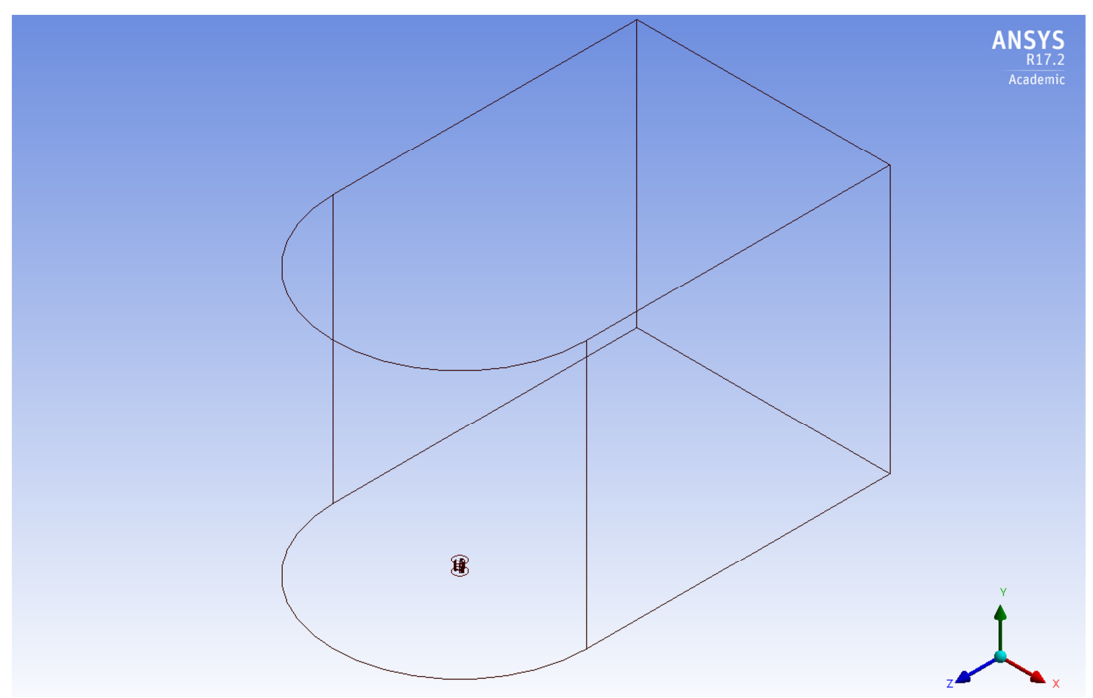

Fig. 2. Farfield of the single C-Rotor

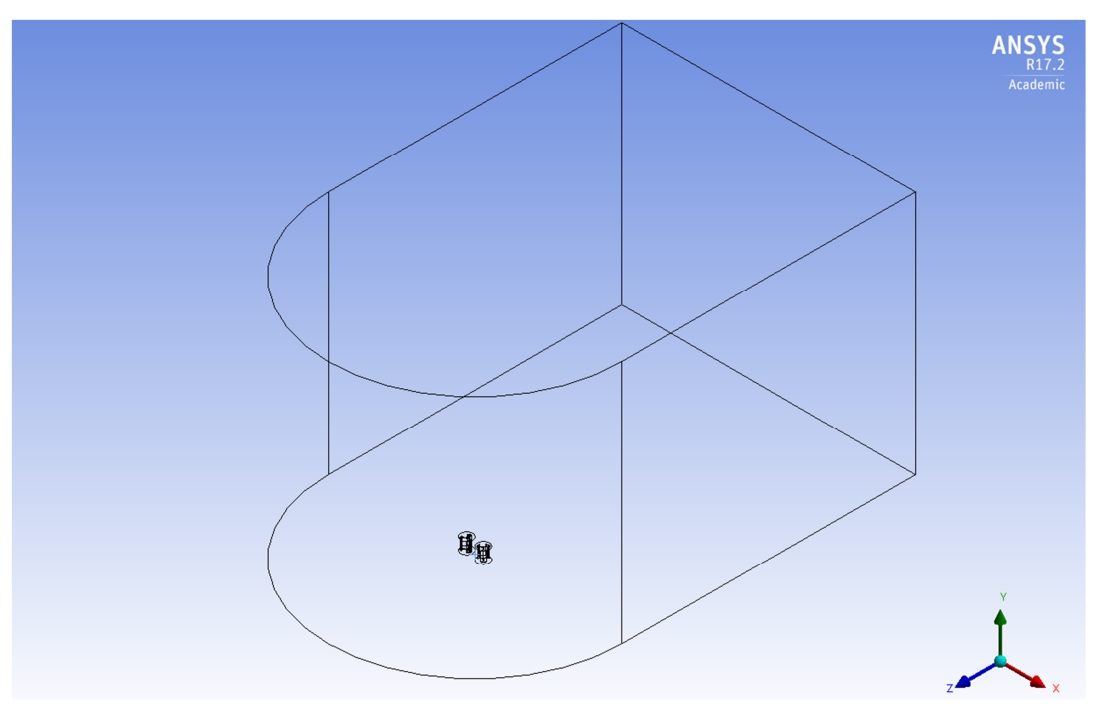

Fig. 3. Farfield of the two Rotor Setup

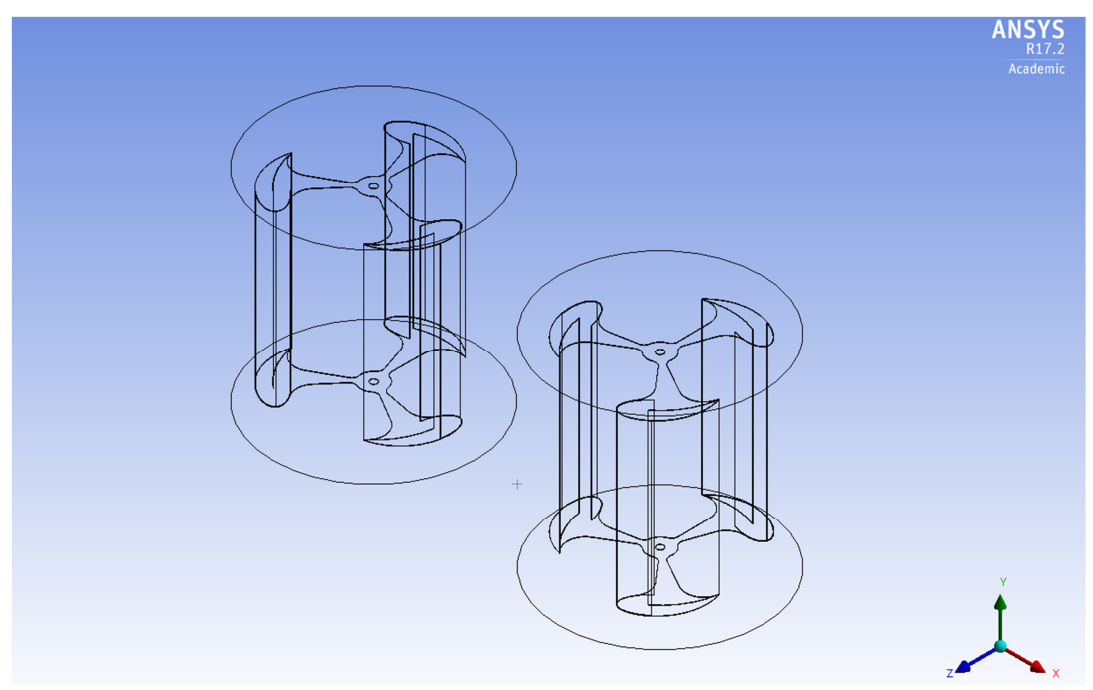

Fig. 4. Two Rotor Setup 


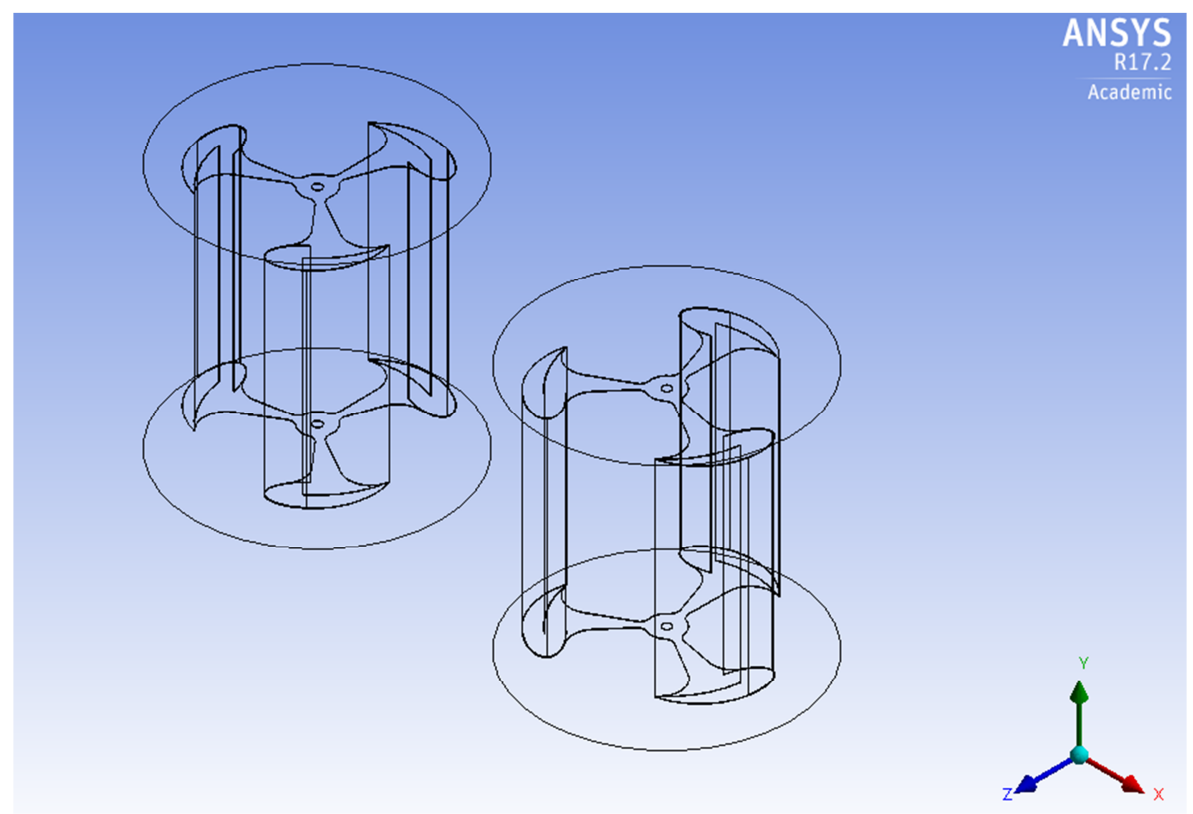

Fig. 5. Two Rotor Setup with reversed Direction of Rotation

In addition to the 3D transient analysis a series of $2 \mathrm{D}$ stationary analysis is performed on a single rotor blade of the c-rotor with a diameter of $1 \mathrm{~m}$. The angle of the flow against the blade is varied in steps of 10 degree in a range from -30 degree to 30 degree. This series of analysis is done in order to examine the lift and drag characteristics of the single c-rotor blade. Especially the potential for optimization of the lift characteristics is of interest in order to move away from the drag driven turbine to a lift driven turbine or at least increase the torque generated via lift. The blade geometry is shown in figure 6 . The farfield around the blade is $25 \mathrm{~m}$ long and $20 \mathrm{~m}$ width, with a length of $10 \mathrm{~m}$ in front of the blade and $15 \mathrm{~m}$ behind the blade. The flow with an angle of 0 degree is the flow in positive $\mathrm{x}$-direction.

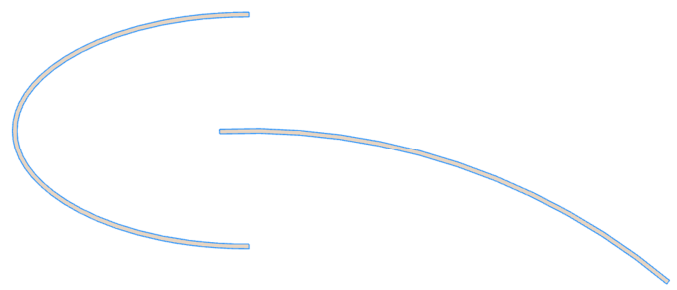

Fig. 6. Single Blade of the C-Rotor

\section{RESULTS AND DISCUSSION}

First the results of the analysis of the single rotor are analyzed. For this purpose, the pressure (Fig. 7) and velocity fields (Fig. 8) at the rotor midplane (plane at half rotor height) are examined for selected time steps. The pressure values are gauge pressure values. It is clear to see that a pressure reduction occurs on the top side of the slat of the forward moving blade, indicating a lift behavior. Inside the slat of the blade at the top and the backward moving blade a slight pressure increase is noticeable. The velocity field shows an overall reduction of the flow velocity due to the rotor. At the slats an increase in velocity is seen, depending on the position of the slat, similar to the velocity increase around an airfoil.

In addition, the $\mathrm{Y}+$ value at the rotor is controlled, it should be in the range of one to five [13]. This way it is secured that the flow at the walls is resolved correctly. As seen in figure 9 the $\mathrm{Y}+$ value is below the given value of five at most of the rotor's surface. In the most front area of the slat however the value exceeds five, indicating that mesh refinement in this area is required for future analysis.

The torque, generated by the rotor, is calculated and plotted over time (Fig. 10). At the beginning of the curve a spike is seen. This spike is neglected for further investigations and the averaged torque is calculated over the second rotation of the rotor $(0.8 \mathrm{~s}$ to $1.6 \mathrm{~s}$ ) and amounts to $0.846 \mathrm{Nm}$. With the torque the power $\mathrm{P}$ is calculated:

$$
P=n \cdot 2 \cdot \pi \cdot M \text {. }
$$

Where $\mathrm{n}$ is the rotational speed in revolutions per second and $\mathrm{M}$ the averaged torque. To calculate the power coefficient $c_{p}$ the wind power is needed:

$$
P_{\text {Wind }}=\frac{1}{2} \cdot \rho \cdot A \cdot u^{3} \text {. }
$$

Where $\rho$ is the air density of $1.225\left[\mathrm{kgm}^{-3}\right], \mathrm{A}\left[\mathrm{m}^{2}\right]$ the rotor area calculated over the diameter and height and $\mathrm{u}\left[\mathrm{ms}^{-1}\right]$ the wind speed. 


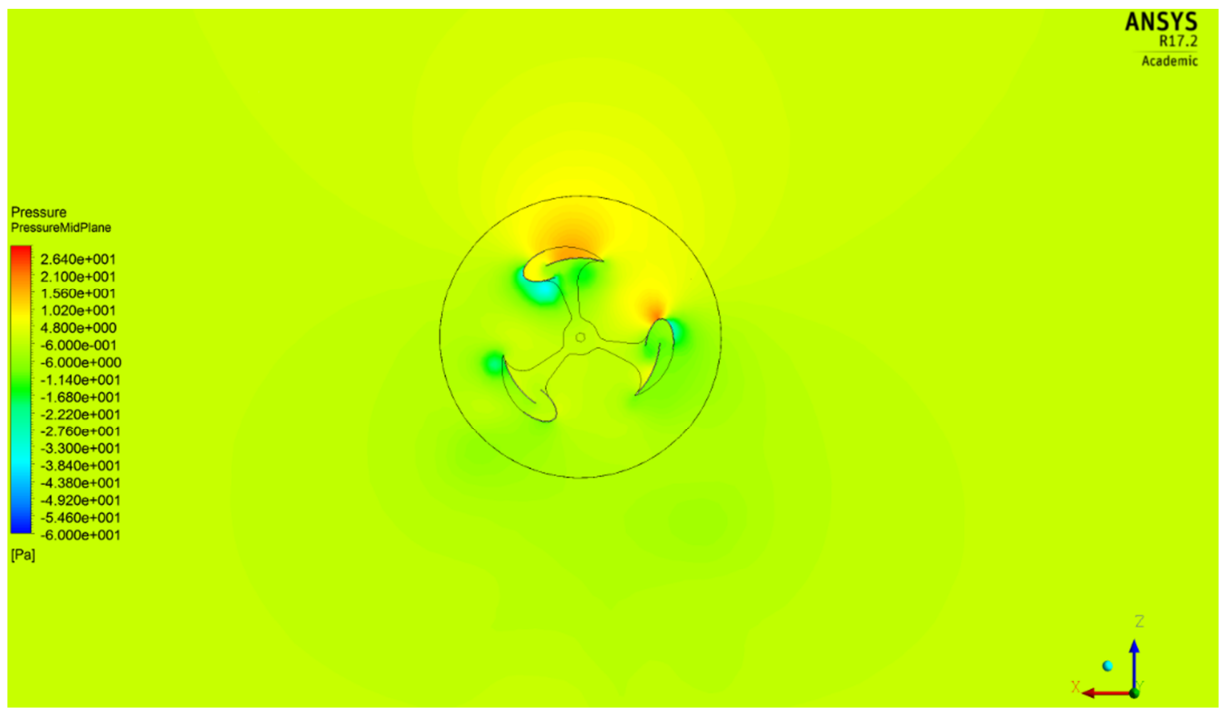

Fig. 7. Pressure field at time 1.425 [s]

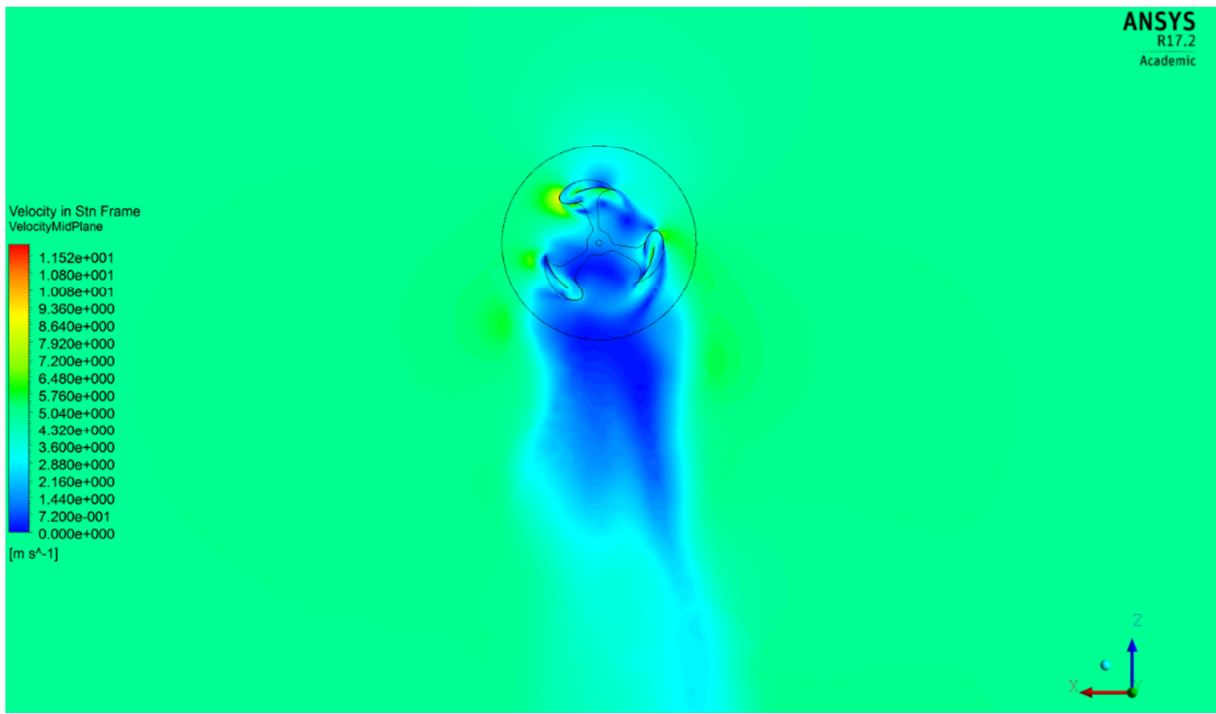

Fig. 8. Velocity field at time $1.425[\mathrm{~s}]$
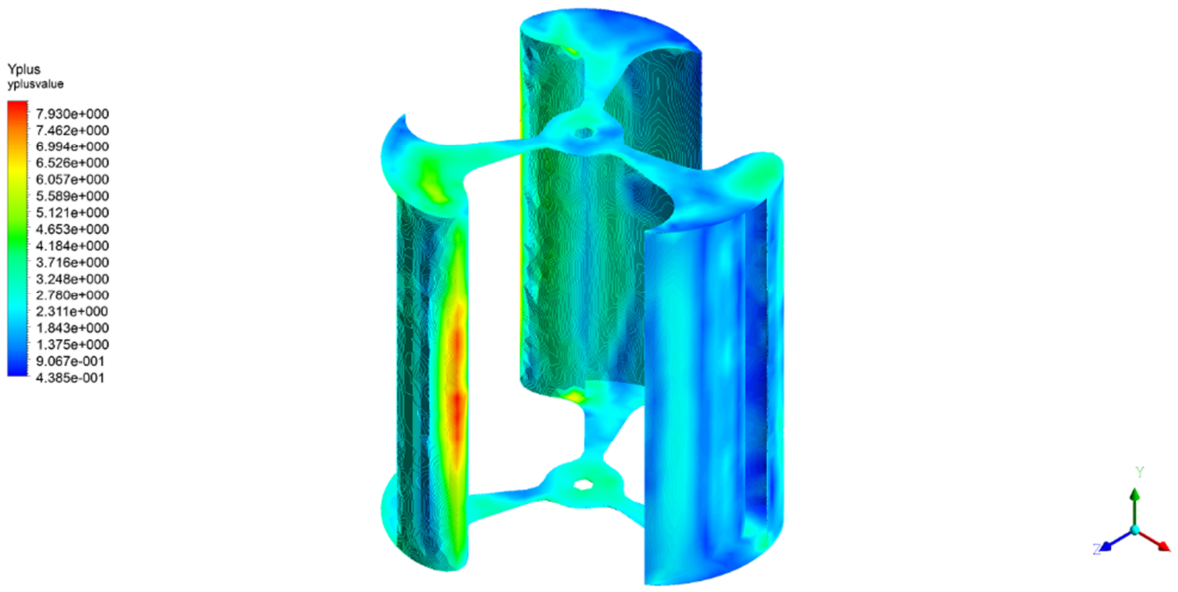

Fig. 9. Y+ Value at the Rotor 


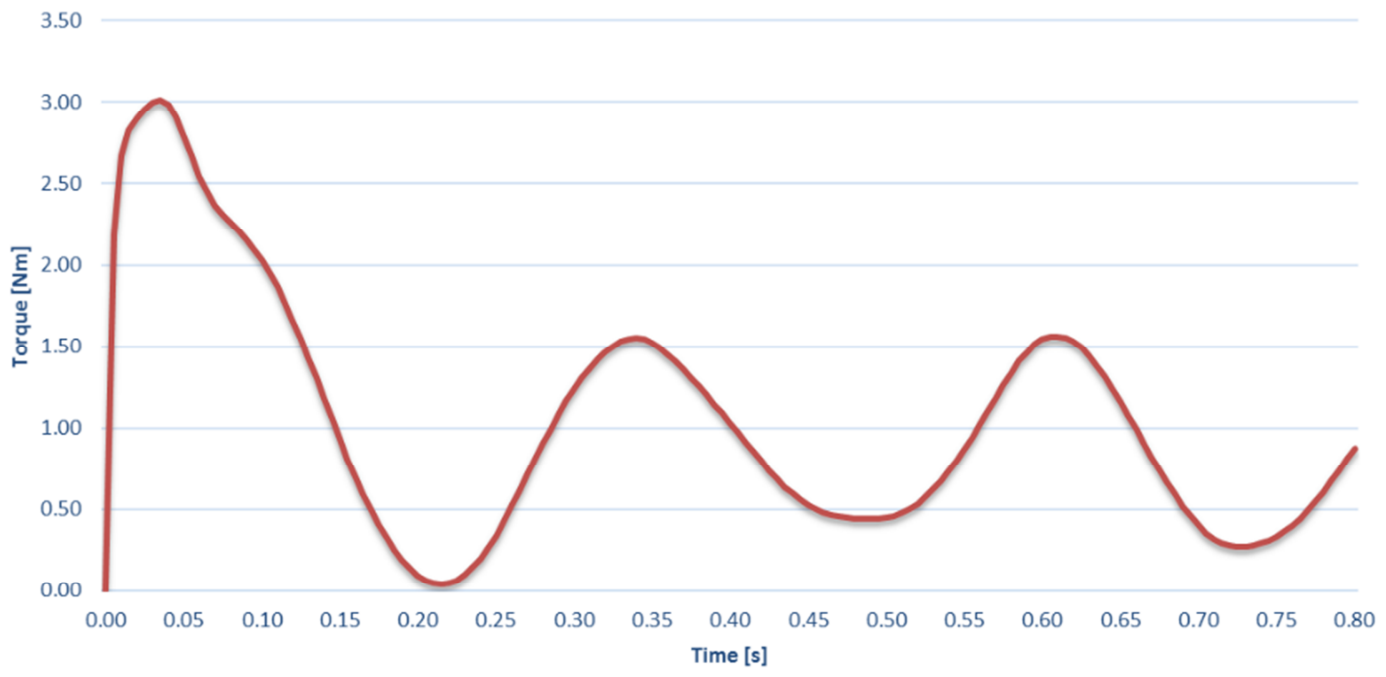

Fig. 10. Torque of the Rotor over time

The power coefficient is then calculated over the ratio of power generated by the rotor to the available wind power:

$$
C_{p}=\frac{P}{P_{\text {Wind }}} .
$$

The power coefficient $c_{p}$ of this rotor is 0.14 . The maximum reachable power coefficient for drag driven turbines is around 0.2 referring to [14]. This means an improvement is still possible.

The analysis of the two other transient 3D analysis follows the same procedure. First the pressure and velocity at the rotor midplane is investigated, seen in figures 12 and 13. A similar behavior compared to the single rotor is seen, with a pressure reduction at the top of the slat of the forward moving blades. Between the two rotors a velocity increase is seen. In order to investigate if the velocity increase influences the power coefficient of the rotors, the second analysis with the two rotor setup but reversed directions of rotation is done. Again, the $\mathrm{Y}+$ values are investigated (Fig. 11). Although the mesh around the rotors was refined by a lot, the values at the tip of the slat still exceed five, indicating further refinement is necessary.
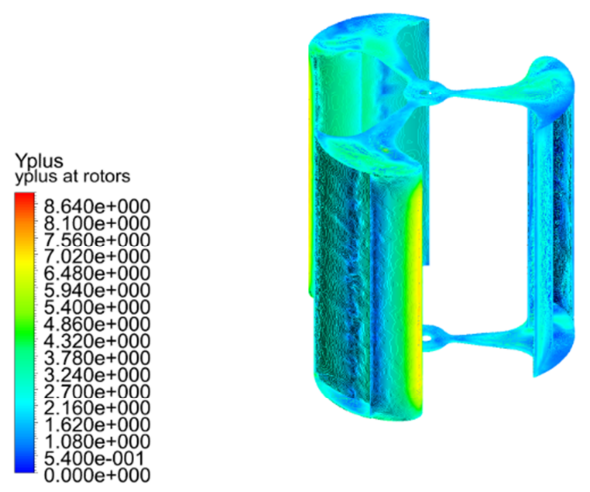

Fig. 11. Y+ Value at the Rotor 


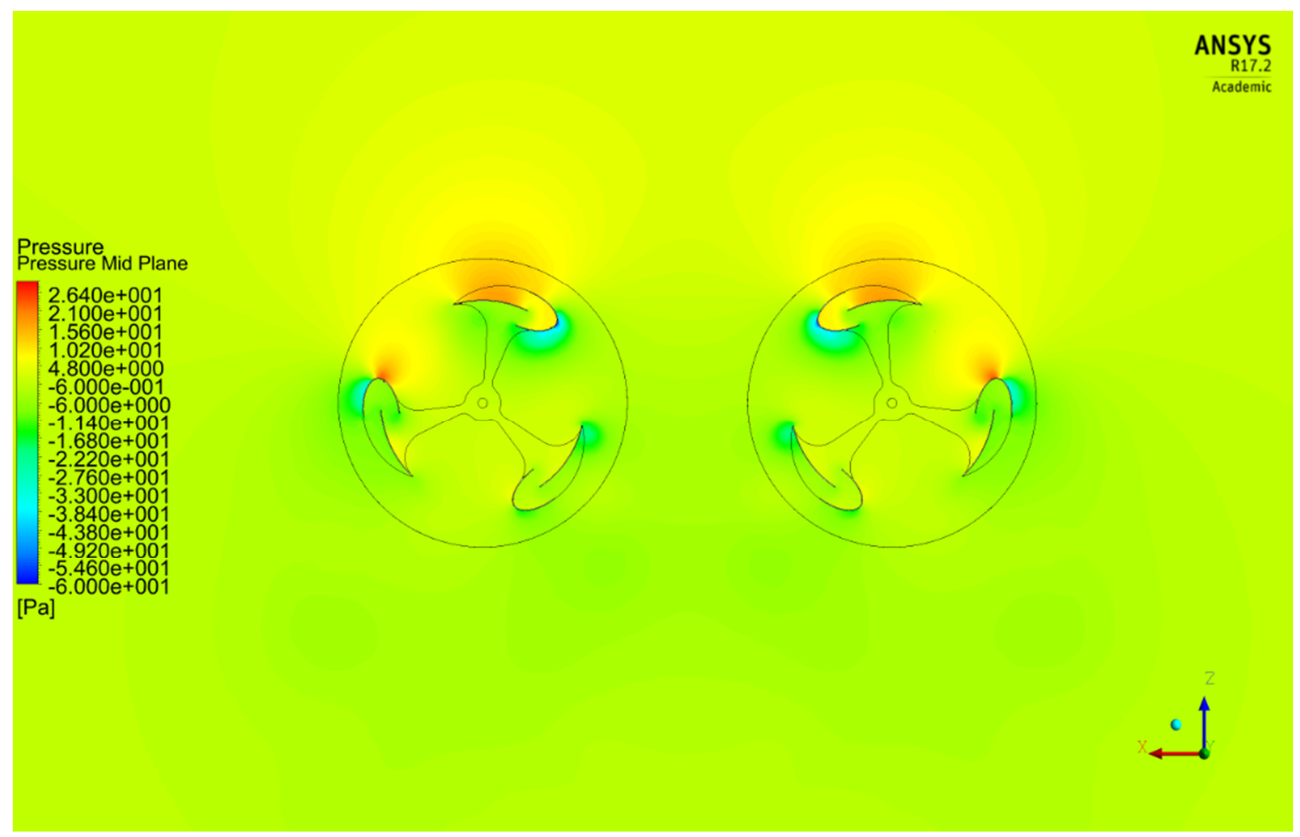

Fig. 12. Pressure field at time $1.78 \mathrm{~s}$

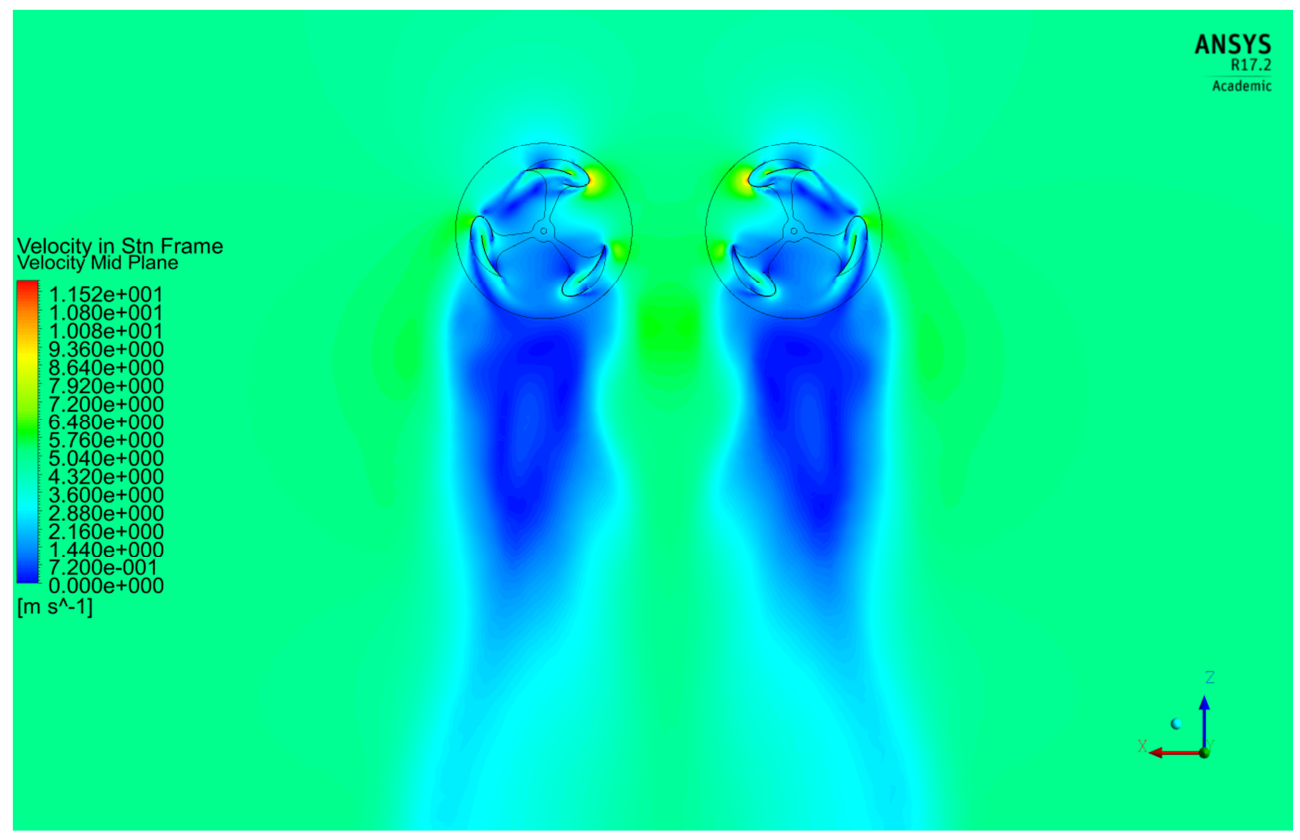

Fig. 13. Velocity field at time $1.78 \mathrm{~s}$

The torque over time plots for both rotors are shown in figures 14 and 15. Figure 14 refers to the rotor on the right side in figure 12 and figure 15 refers to the rotor on the left side in figure 12. As expected, both torque curves look very similar. Again, the spike at the beginning is neglected. The averaged torques for both rotors are again calculated over the second rotation ( $1 \mathrm{~s}$ to $2 \mathrm{~s}$ ). The averaged torque of both rotors is $1.66 \mathrm{Nm}$. This leads to a power coefficient of 0.141 for both rotors, calculated with equations 1 to 3 . This is a slightly higher power coefficient then for the rotor with $0.8 \mathrm{~m}$ diameter. Overall the two rotor setup doesn't seem to have a negative effect on the power coefficient. 
6.00

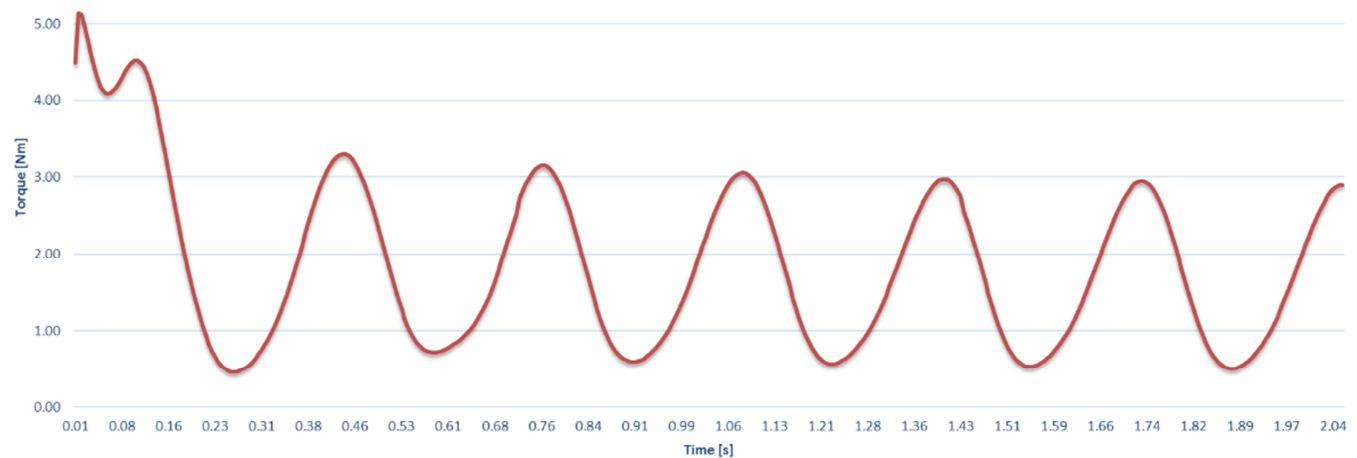

Fig. 14. Torque of the first Rotor over time

6.00

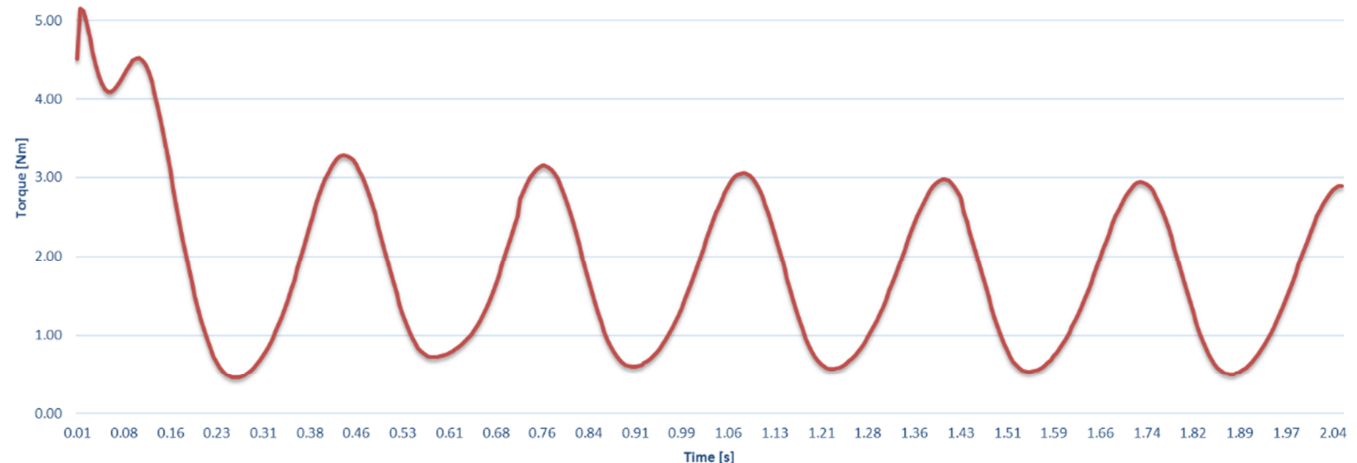

Fig. 15. Torque of the second Rotor over time

For the two rotor setup with reversed directions of rotation, the pressure and velocity at the rotor midplane are shown in figures 17 and 18. Overall this setup shows a similar behavior as the other two rotor setup. The velocity increase between the rotors is in the same range as before. The most noticeable difference is the velocity field behind the rotors. This could be of interest if more than two rotors are installed. The $\mathrm{Y}+$ values fall in the same range as before (Fig. 16), since the same mesh settings are used.

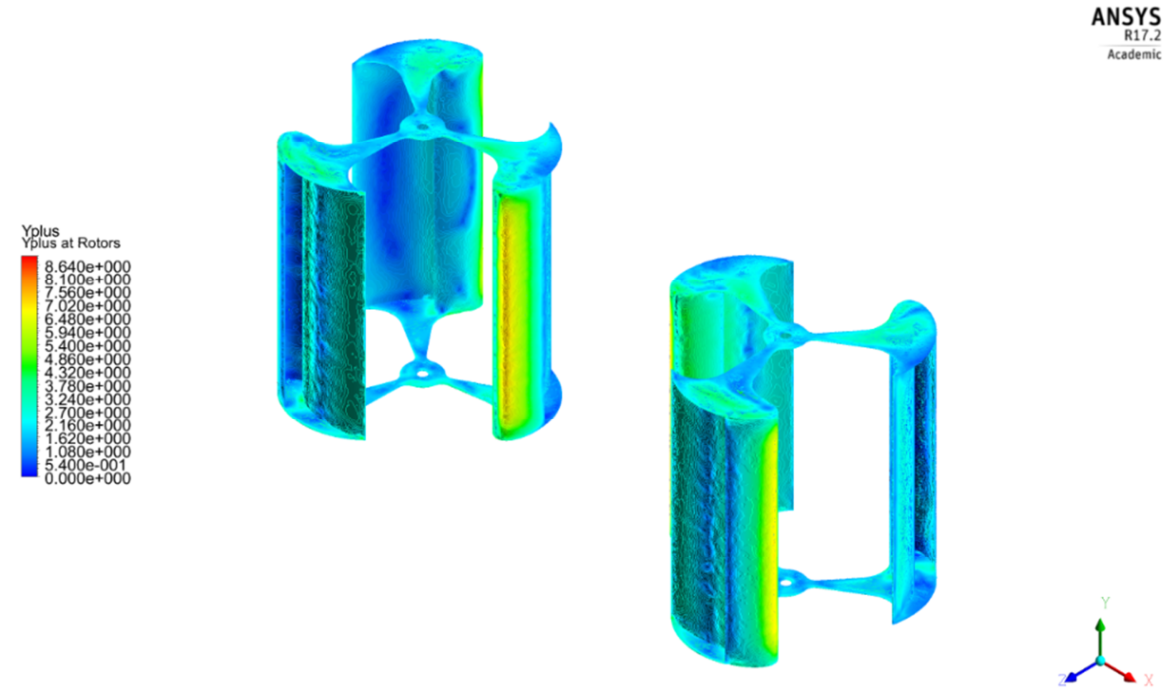

Fig. 16. Y+ Value at the Rotors, reversed direction of rotation 


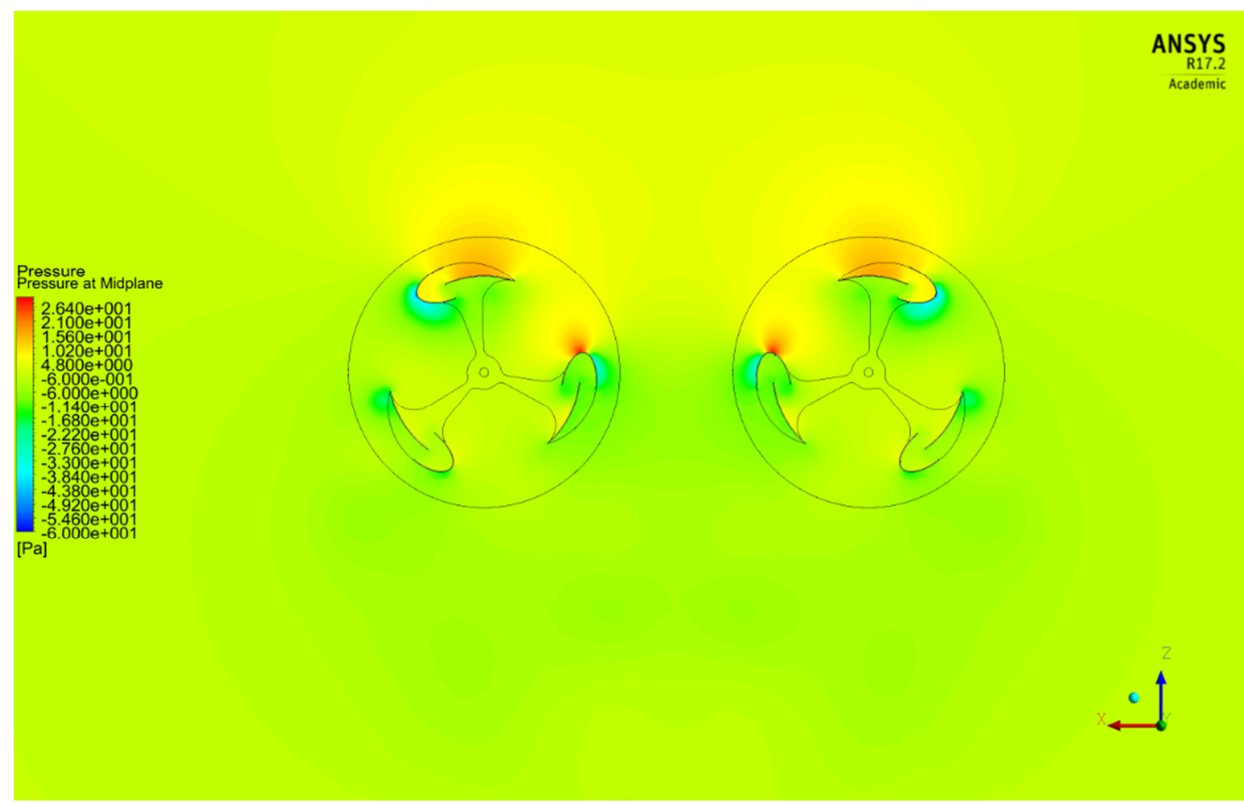

Fig. 17. Pressure field at time $1.78[\mathrm{~s}]$, reversed direction of rotation

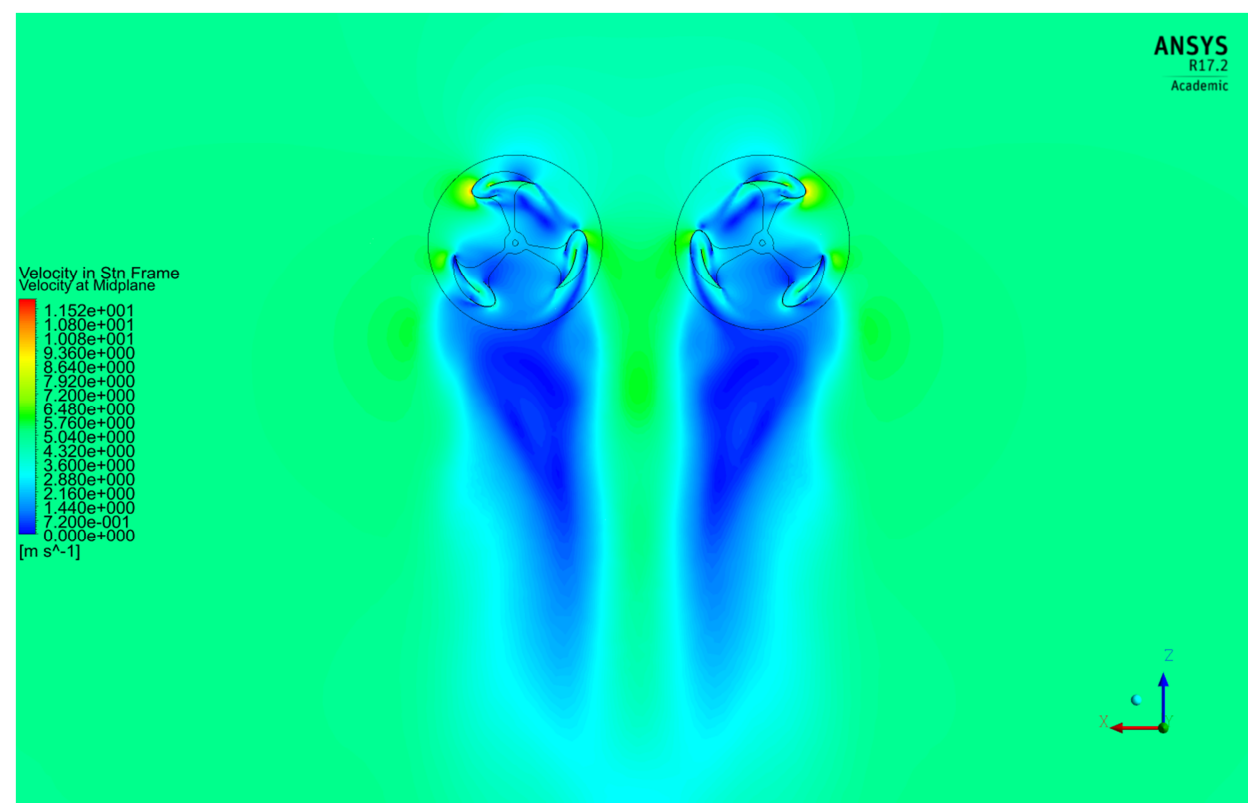

Fig. 18. Velocity field at time 1.78 [s], reversed direction of rotation

The torque over time plots are shown in figures 19 and 20. Again, the curves look similar with a spike at the beginning. Also, the curves of both directions of rotation are very close to one another, indicating that the influence of the direction of rotation isn't that high for the chosen rotor distance. The averaged torque is calculated the same way as before (neglecting the spike at the beginning and calculating the average torque over the second rotation between $1 \mathrm{~s}$ and $2 \mathrm{~s}$ ) and amounts to $1.64 \mathrm{Nm}$ foreach rotor leading to a power coefficient of 0.139 . This coefficient is slightly lower than before. In the future of this project different distances between the rotors will be investigated. Especially smaller distances are of interest. It is possible that the rotors have a positive effect on one another at a certain distance [7]. The idea here is to make use of the velocity increase between the rotors. 


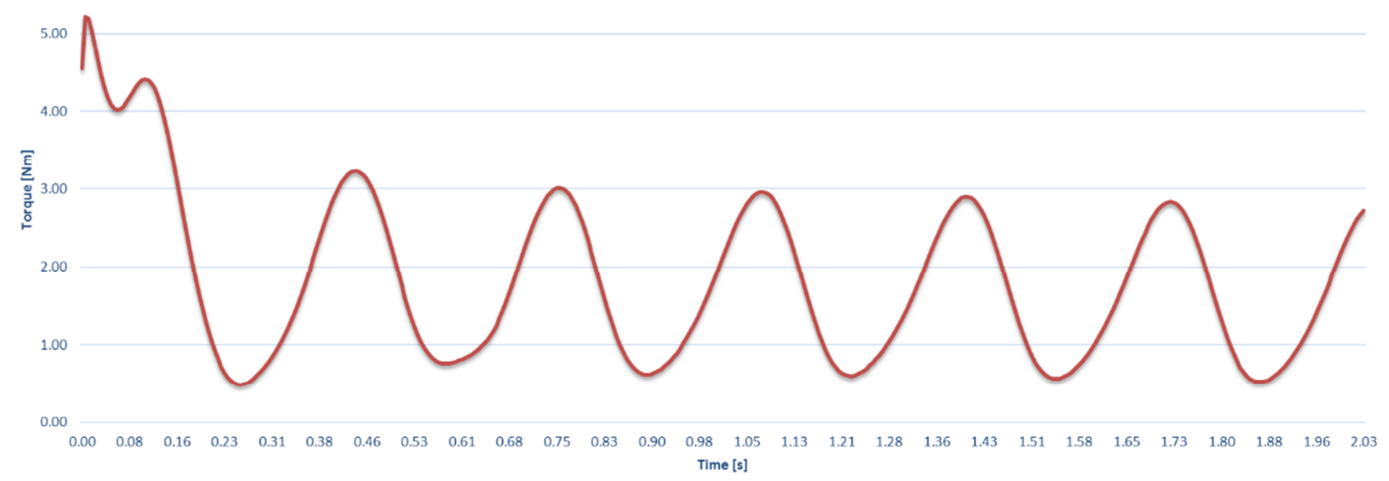

Fig. 19. Torque of the first Rotor over time, reversed direction of rotation

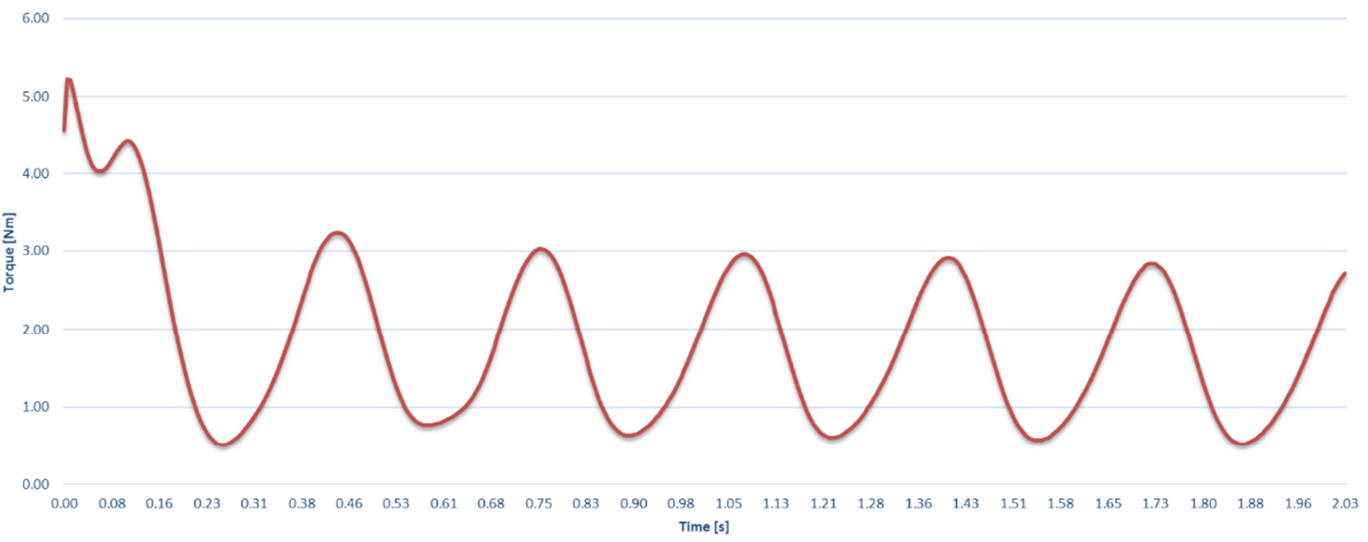

Fig. 20. Torque of the second Rotor over time, reversed direction of rotation

For the $2 \mathrm{D}$ analysis the lift coefficients $\left(c_{l}\right)$ and drag coefficients $\left(c_{w}\right)$ are investigated. For the calculations of those values some reference values are needed [15]. These values are the air density $\rho$ of $1.225\left[\mathrm{kgm}^{-3}\right]$, the airspeed $\mathrm{u}$ of $5\left[\mathrm{~ms}^{-1}\right]$, the chord length of the profile of 0.436 [m] and the unit depth of $1 \mathrm{~m}$. In addition, the torque coefficient $\left(c_{m}\right)$ with regards to the rotation point of the rotor is calculated. In order to calculate the torque coefficient a length as another reference value is needed. For this length the distance to the rotation point of the rotor of 0.424 [m] is chosen. The values for the different angles of attack of the rotor blade are listed in table 1. For the positive angles of attack an increase in lift and drag can be seen until the $20^{\circ}$ angle, after this angle the lift decreases while the drag keeps increasing. This makes sense since the aerodynamic lift effect decreases at high angles of attack, while the area of the blade in flow direction increases, which leads to a higher drag. For the negative angles of attack a lower drag coefficient, even lower than the coefficient at 0 degree, is seen. This is an unexpected result at first. However, a reason for the lower drag coefficient could be that the rounded baffle opposes less drag for the flow at negative angles of attack. The lift behaves as expected and is directed in the opposite direction as opposed to the lift at positive angles of attack. The torque coefficient values behave analogue to the lift. With an increase in lift, an increase in torque is seen. This further shows the potential of an increase of the power coefficient by optimizing the lift behavior of the rotor blades. In figures 21 to 23 the velocity for angles of attack of $0,-10$ and 10 degree is shown. In the simulation, the position of the profile was kept the same while the direction of the flow was changed, this has the same effect as moving the blade relative to the flow. For an angle of attack other than 0 degree the total flow velocity is split into its $x-$ and $y-$ components. For example, for an angle of attack of -10 degree the flow velocity has a component in positive $\mathrm{x}$ - and negative $\mathrm{y}$-direction. Analogue to the lower drag coefficients it can be seen that the impact on the flow velocity is much smaller for negative angles of attack due to the rounded baffle, which is completely in the slipstream of the slat for an angle of attack of 10degree. At the slat a similar behavior to airfoils is seen with a velocity increase on one side, depending on the angle of attack. Further investigations of the 2D blade geometry are ongoing to verify the results obtained so far. 


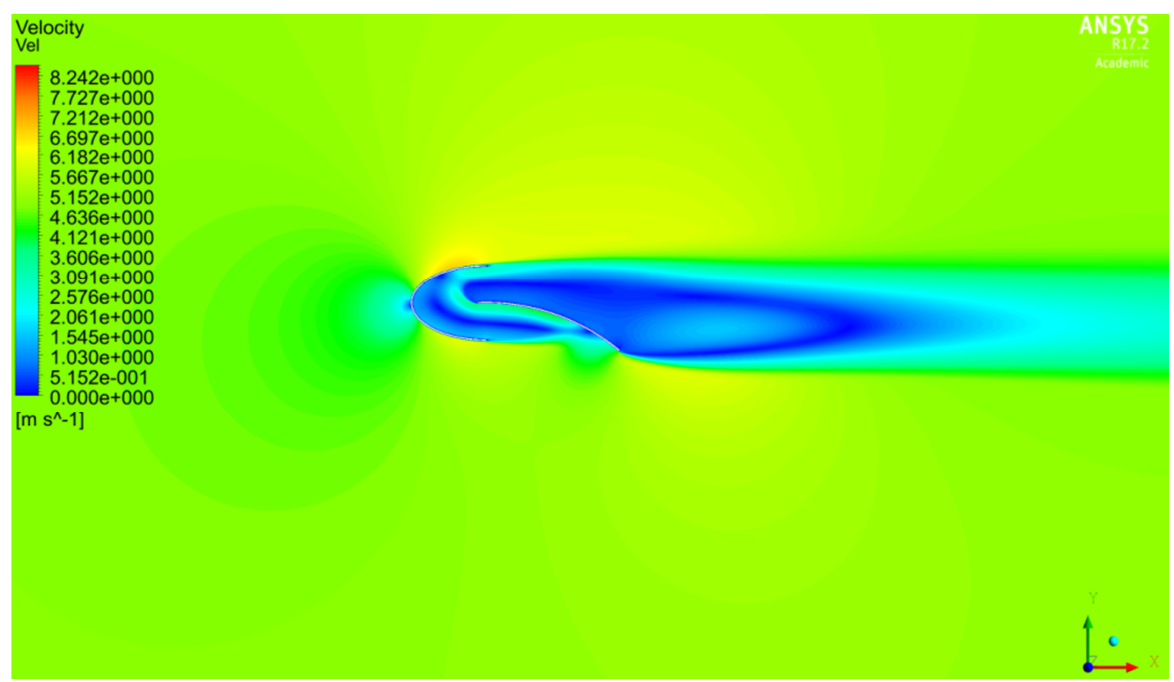

Fig. 21. Velocity field at an angle of attack of 0 degree

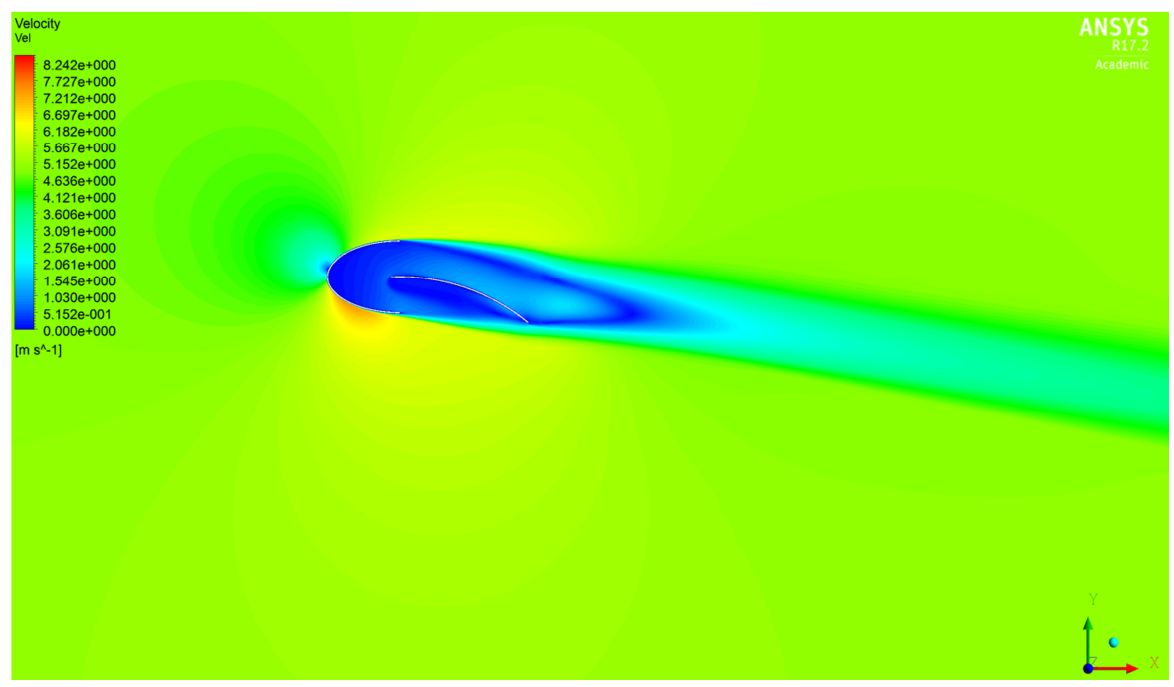

Fig. 22. Velocity field at an angle of attack of -10 degree

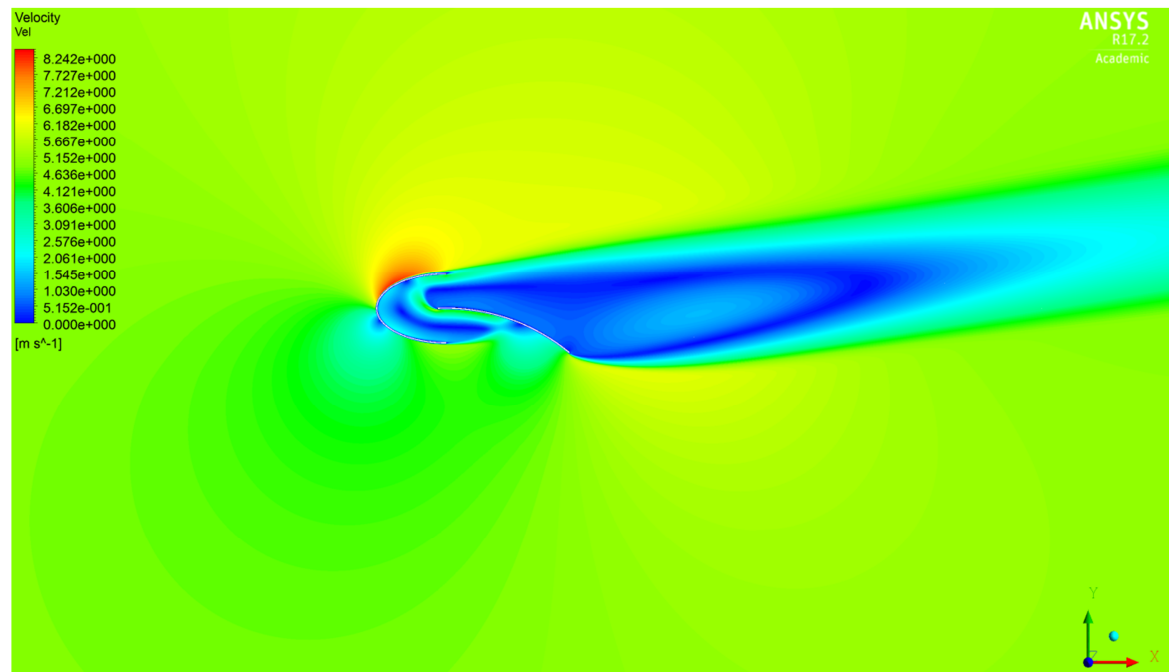

Fig. 23.Velocity field at an angle of attack of 10 degree 
Tab. 1. $c_{1}, c_{w}$ and $c_{m}$ values of the blade profile

\begin{tabular}{cccc}
\hline $\begin{array}{c}\text { Angle of } \\
\text { Attack }\end{array}$ & $c_{l}$ & $c_{w}$ & $c_{m}$ \\
\hline$-30^{\circ}$ & -0.29 & 0.27 & -0.0212 \\
\hline$-20^{\circ}$ & -0.43 & 0.18 & 0.0671 \\
\hline$-10^{\circ}$ & -0.31 & 0.16 & -0.0389 \\
\hline $0^{\circ}$ & 0.51 & 0.23 & -0.0883 \\
\hline $10^{\circ}$ & 1.15 & 0.31 & 0.0177 \\
\hline $20^{\circ}$ & 1.35 & 0.45 & 0.1696 \\
\hline $30^{\circ}$ & 1.15 & 0.72 & 0.1342 \\
\hline
\end{tabular}

\section{VALIDATION AND VERIFICATION}

In order to validate the calculations two other meshes, one coarser one and one finer one, were created. The original mesh has 8 million elements, the coarser mesh has 4 million elements and the finer mesh has 10 million elements. Preferably the refinement ratio of the finer mesh would be higher. While the creation of a mesh with a higher number of elements is possible the computational resources aren't there to calculate the results in a timely manner. The results of the very coarse mesh with 4 million elements are far off with a calculated power coefficient $c_{p}$ of 0.087 . The finer mesh yields a value of 0.146 for the power coefficient $c_{p}$. The values of the original and the refined mesh lie in the same range leading to the assumption that the mesh is fine enough to give a good estimation of the torque and power coefficient of the rotor. Additionally, the velocity and pressure fields show a similar picture, differences can be seen in the fields of the coarse mesh. In table 2 the results for all three meshes are shown. For a more extensive mesh study more computational resources and more time is needed.

The results of the calculation are compared to experimental results in [9]. The power coefficient measured for the corresponding tip-speed ratio was 0.11 . However, the rotors were much smaller and it can be assumed that larger rotors will result in higher $c_{p}$-values. This leads to the conclusion that the results are sufficient for a first estimation of the rotor behavior.

Tab. 2. Comparison of the three meshes

\begin{tabular}{cccc}
\hline Mesh & $\begin{array}{c}\text { Number of } \\
\text { Elements }\end{array}$ & $c_{p}$ & $\begin{array}{c}\text { Average } \\
\text { Torque } \\
{[\mathrm{Nm}]}\end{array}$ \\
\hline Coarse & 4 Million & 0.087 & 1.021 \\
\hline Original & 8 Million & 0.141 & 1.66 \\
\hline Fine & 10 Million & 0.146 & 1.721 \\
\hline
\end{tabular}

\section{SUMMARY AND OUTLOOK}

It can be said that there is indeed potential to increase the lift effect of the profile of the c-rotor [3]. Also, different stackings of turbines [6] and the varying of the distance between rotors [7] might have positive effects. Further investigations are conducted in the next steps of this project. This includes the further analysis of the blade geometry, analysis of different turbine stackings as well as the distances between the rotors. With the help of those analysis, the blade geometry will be optimized and the most efficient rotor setup determined. The optimization of the blade geometry will be done using the adjoint approach, calculating the sensitivities to the shape of the lift to drag ratio and the torque. With those results a modification of the geometry is possible. Fluent provides a tool for such calculations and optimizations. The goal is to develop an easy to install, long-lasting, cheap and effective small wind turbine where different array sizes are realizable depending on the local needs and available space.

\section{References}

1. Czisch G., Durstewitz M., Hoppe-Kilpper M., Kleinkauf, W. (1999). Windenergie gestern, heute und morgen. In: Husum Wind '99. Kongreßband: Messe und Fachkongreß für Windenergie, Husum, Germany, 22-26 September, pp. 56-69.

2. Henze A., Schröder W. Fahrzeug- und Windradaerodynamik - Windturbines, AIA RWTH Aachen, viewed 11 April 2019, http://www.aia.rwthaachen.de/vlueb/vl/fahrzeug-

_und_windradaerodynamik/material/windkraftanlagen_e nglish.pdf

3. Schubel P.J., Crossley R.J. (2012). Wind Turbine Blade Design. Energies, Vol. 5, No. 9, pp. 3425-3449.

4. Hau E. (2016). Windkraftanlagen: Grundlagen,Technik, Wirtschaftlichkeit. Springer, Heidelberg.

5. Von Canstein R. (1991). German Patent No. DE 4120 908 C2. Retrieved from https://register.dpma.de/DPMAregister/pat/PatSchriftene insicht?docId=DE000004120908C $2 \&$ page $=1 \&$ dpi $=300$ \&lang=de\&full=true

6. Kumbernuss J., Chen J., Yang H.X., Lu L. (2012). Investigation into the relationship of the overlap ratio and shift angle of double stage three bladed vertical axis wind turbine(VAWT). Journal of Wind Engineering and Industrial Aerodynamics, Vol. 107-108, pp. 57-75.

7. Dabiri J.O. (2011). Potential order-of-magnitude enhancement of wind farm power density via counterrotating vertical-axis wind turbine arrays. Journal of Renewable and Sustainable Energy, Vol. 3, No. 4, pp. 043104

8. Ragheb M. (2014). Optimal Rotor Tip Speed Ratio. University of Illinois, http://mragheb.com/ NPRE\%20475\%20Wind\%20Power\%20Systems/Optima 1\%20Rotor\%20Tip\%20Speed\%20Ratio.pdf

9. Furtmayr F. (2013). Windkraftanlagen mit vertikaler Achse (VAWT): Der C-Rotor im Windkanalversuch und Strömungssimulation in Star-CCM+. B. Eng. Thesis. Hochschule für angewandte Wissenschaften Ingolstadt.

10. Hu Y., Wang T., Jin H., Cao X., Zhang C. (2017). Experimental study on aerodynamic characteristics of vertical-axis wind turbine. International Journal of 
Smart Grid and Clean Energy, Vol. 6, No. 2, pp. 104113.

11. Böcker J., Lange H. (2015). Windenergie - Potenziale auf Dächern. fk-wind, Institut für Windenergie, Hochschule Bremerhaven and STÄWOG Bremerhaven $\mathrm{mbH}$.

12. Bagal N.L., Singh B., Pardyjak E.R., Brwon M.J. (2004). Implementation of Rooftop Recirculation Parameterization into the QUIC Fast Response Urban Wind Model. In: Fifth Conference on Urban Environment, University of Utah, Salt Lake City, UT, 22-26 August, paper no. J6.10

13. ANSYS Inc. Fluent User's and Theory Guide.

14. BWE Bundesverband WindEnergie, Widerstands- und Auftriebsläufer, BWE Bundesverband WindEnergie, viewed 10 April 2019, https://www.windenergie.de/themen/anlagentechnik/funktionsweise/widers tandlaeufer-auftriebslaeufer/

15. Rill S. Aerodynamik des Flugzeugs, Hochschule Bremen, viewed 10 April 2019, http://homepages.hsbremen.de/ kortenfr/Aerodynamik/script/content.html

\section{Biographical notes}

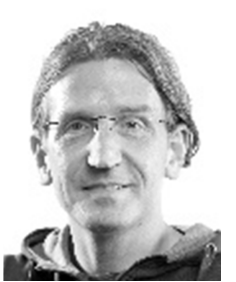

Frank Kortenstedde received his Dipl.-Ing. degree in Mechanical engineering specializing in aerospace engineering from University of Applied Sciences Bremen in 1998. He received furthermore his M.Sc. degree in Industrial Engineering in 2007 from Beuth University of Applied Sciences Berlin and his Dr.-Ing. degree from the Clausthal University of Technology in 2016. Since 2008 he has been a researcher in the Institute of Aerospace Technology at the University of Applied Sciences Bremen, where currently he works as a research assistant and head of Department wind turbines. His scientific interests focus on aerodynamic problems concerning optimization and efficiency increase of rotor blades. He has participated in 2 national research projects, presenting results of his work at 2 international and 2 national conferences, published more than 10 scientific papers in international and national journals, book chapters, as well as conference proceedings. He is also the author of 2 national patents.

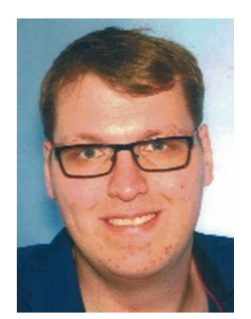

Jan Stief received his B. Eng. degree in aerospace engineering from University of Applied Sciences Bremen in 2017. Currently he is studying Aerospace Technologies at University of Applied Sciences Bremen to receive his M.Sc. degree. Before he started studying he completed an apprenticeship as an aircraft mechanic in 2011. Together with Mr. Kortenstedde he is working on the VAWT project. Currently he is working on his master thesis, also in the area of wind energy. 
